\title{
LA CRISIS DE LAS HUMANIDADES
}

\author{
Carla Cordua \\ Universidad de Chile \\ carla.cordua@gmail.com
}

\begin{abstract}
Resumen
La noción de una crisis actual de las humanidades procede del ensayo de la escritora norteamericana Martha Nussbaum, autora de Sin fines de lucro. Por qué la democracia necesita de las humanidades. Ilustramos la vigencia de esta crisis de alcances universales mediante algunas de las tesis que la explican y describimos un par de rasgos de la influencia que ha tenido sobre la educación chilena.
\end{abstract}

PALABRAS ClaVe: humanidades, educación, civismo, ciudadanía democrática.

\section{Abstract}

The idea of a current universal crisis of the humanities belongs to Notforprofit, a recent book written by Martha Nussbaum, the wellknown American essayist. We describe some features of this crisis and comment on its influence on the school curricula in Chile.

KEY WORDS: humanities, education, civism, democraticcitizenship.

RA Cuando hablamos hoy de 'humanidades' ya no nos referimos a la concepción renacentista nombrada de esta manera, la cual fue cuestionada y dejada atrás durante el siglo pasado. Usamos esta designación, en cambio, para un grupo de disciplinas que formaban parte de todos los niveles de la educación formal que se impartía todavía hace algunas décadas. Estas disciplinas comprenden a la filosofía, la historia, la lingüística, las ciencias sociales y políticas, las artes y la literatura, el derecho, ciertas variantes de la sicología y la antropología y algunos aspectos de las ciencias estrictas y las especiales de la naturaleza. Estas materias humanísticas y su presencia en los actuales programas educativos de todos los niveles pasan, en este momento, por una profunda crisis a la que se presta poca atención a pesar de su gravedad. El afán de contribuir al crecimiento económico de los países que se consideran atrasados y la determinación de conservar los niveles de bienestar y de consumo en las naciones ricas inclinan hoy a los planificadores de la educación a programar la formación de los educandos teniendo en vista principalmente los intereses pecuniarios de los individuos y de su nación.

El adiestramiento técnico y la enseñanza puramente utilitaria de aplicaciones del conocimiento científico ocupan cada vez más exclusivamente los programas lectivos de todos los niveles formativos en una gran mayoría de los países del mundo. Esta 
poderosa tendencia internacional sacrifica el tiempo antes destinado a las disciplinas humanísticas, cuyo sentido era la formación de una personalidad compleja y matizada, la preparación para una coexistencia social civilizada y para el desempeño de una ciudadanía consciente y responsable. En el presente, los estudios humanísticos han sido gravemente recortados, arrinconados y pasados a llevar por la ola de la preocupación económica y el predominio de un ventajismo miope y manipulador, incapaz de verse como tal y de reconocer lo que sacrifica.

Una notable ensayista norteamericana ha escrito un libro sobresaliente sobre los peligros que trae consigo el debilitamiento progresivo de las aspiraciones y de los ejercicios intelectuales ligados de cerca a los estudios humanísticos. La pérdida de la cultura humanística, sostiene la autora, traerá consigo la ruina de las sociedades democráticas, las que necesitan que sus ciudadanos sean capaces de pensar independientemente, de concebir soluciones y vías alternativas para las decisiones prácticas, de respetarse a sí mismos y respetar a otros, de comprender la conducta ajena y ser capaz de ponerse en el caso de otras personas. Aunque no tan visible y comentada, la crisis de las humanidades es la verdadera crisis del mundo actual, no el terremoto de los mercados bursátiles al que el periodismo trata como si fuera lo único importante que está ocurriendo en el momento.

Este libro lúcido y revelador de Martha Nussbaum se llama en el original "Notforprofit" ya fue traducido al castellano en España bajo el título "Sin fines de lucro. Por qué la democracia necesita de las humanidades" (Katz Editores, Madrid). Leerlo significa recuperar una conexión directa con lo que sucede a nuestro alrededor, que no siempre reconocemos claramente debido a que nos es presentado a menudo bajo apariencias engañosas. Somos inducidos a convertirnos en productores de bienes monetarios mediante técnicas y conocimientos de los que depende la creciente movilización de los mercados y los consumidores. Pero nada garantiza que las personas entrenadas solo en generar ingresos sean capaces de construir sociedades en las que valga la pena vivir. El libro de Nussbaum es también una lección en pensamiento crítico que nos hace mucha falta, y del que se puede decir que nunca es demasiado tarde para aprender a practicarlo.

Ofrezco más adelante un resumen de algunos planteamientos que este libro propone y que resultan instructivos para nosotros en este momento. Creo que en circunstancias en que la validez y la pertinencia de nuestro sistema educacional están siendo cuestionadas por numerosos grupos ciudadanos, resulta oportuno abrirse a la consideración crítica no solo de los problemas locales sino también a la de las grandes corrientes de la opinión internacional. Entre nosotros hemos asistido en los últimos años con alarma a la reducción del tiempo que se le solía dedicar en la educación secundaria a la Filosofía. Las reiteradas protestas de los profesores que impartían estas clases no fueron escuchadas por las autoridades a cargo de la revisión de los programas vigentes. A pesar de que sus críticas eran obviamente persuasivas, no fueron tenidas en cuenta por las últimas reformas practicadas por el Ministerio de Educación a los contenidos lectivos de este nivel. Este es un buen ejemplo local de lo que Martha Nussbaum llama la crisis de las humanidades: la reducción del tiempo que se le dedica a las materias filosóficas y la facilidad con la que se las remite a un lugar subordinado cuando no se 
las suprime del todo. Estas decisiones y recortes se hacen sin siquiera hacerse cargo de las consecuencias que se siguen de tales medidas. Un caso ilustrativo interesante de esta tendencia ofrece la desaparición injustificada, hace ya numerosas décadas atrás, de la educación cívica, una materia que formaba parte de los programas secundarios y cuya importancia para el cultivo de una ciudadanía consciente y alerta no puede ser exagerada.

La tesis del libro de MarthaNussbaum acerca de la crisis de las humanidades es que esta es una tendencia universal negativa que avanza y se profundiza sin que se le preste la debida atención. Aunque la autora enfoca el proceso crítico en los casos particulares de la educación en los EE.UU. de América y en el de la India, es obvio que, al ligarlo estrechamente con los procesos de desarrollo económico que absorben los intereses y los esfuerzos de todos los países comprometidos en la globalización, su exposición adquiere el alcance global de los tiempos que corren. La preocupación de los líderes actuales por el futuro de sus naciones se concentra en el lucro (theprofit motive). No objetamos, sostiene el ensayo, el hecho de que se ofrezca una buena educación científica y técnica; tampoco nos oponemos a los esfuerzos que preparan para favorecer el progreso económico: nuestra preocupación concierne a las posibilidades humanas descuidadas por esta clase de preparación. "Mi preocupación es que esas otras habilidades, igualmente decisivas, están en peligro de perderse en el jaleo competitivo, habilidades internamente cruciales para la salud de cualquier democracia y para la creación de una cultura mundial decente capaz de abordar constructivamente los problemas más urgentes del mundo" (p. 7).

Nussbaum se refiere a las habilidades personales, sociales y políticas asociadas a una educación en las materias humanísticas, en las artes, en el pensamiento crítico, en la reflexión y la comprensión de los otros y de sí. Comparando una formación que prepara específicamente para actividades lucrativas con una más abarcadora, que tiene en vista cierta clase de coexistencia social y de ciudadanía, concluye que la segunda es recomendable tanto para los niveles primarios y secundarios como también para la educación universitaria. En todas las etapas de la formación de una personalidad compleja y diversa, hay funciones específicas que dependen casi exclusivamente de las materias humanísticas. La autora no niega el aporte específico que las ciencias, en especial las sociales y económicas, hacen, junto con las humanísticas, a la formación del ciudadano civilizado; pero entiende que su tarea principal debe ser ahora destacar aquello que, aunque precioso, está a su juicio descuidado y profundamente amenazado. Una cultura capaz de renovarse creadoramente necesita fuerzas que no procedan exclusivamente de una educación para el lucro (educationforprofit) o de una inspirada solo en el crecimiento económico (educationforeconomicgrowth) (p. 10).

"Cuando son, además, puestas en práctica en su mejor versión, estas otras disciplinas [las humanísticas] están penetradas por lo que podríamos llamar el espíritu de las humanidades: que reside en el cultivo del pensamiento crítico, de la imaginación atrevida, de la comprensión enfática de las experiencias humanas de muchas clases diferentes y también de la comprensión de la complejidad del mundo en el que vivimos" (p. 7). 